\title{
Prevalence of overweight and obesity in grade five students in schools of Gampaha Medical Officer of Health area.
}

\author{
U. Perera', Chrishantha Abeysena ${ }^{2}$
}

\begin{abstract}
Introduction

Overweight in childhood is an emerging health problem in developing countries.

\section{Objective}

To determine the prevalence of overweight and obesity among grade five school children in schools of Gampaha Medical Officer of Health(MOH) area.

\section{Methods}

A descriptive cross sectional study was carried out among the grade five students in government and private schools in Gampaha MOH area during September and October 2007. Nine schools from a total of 46 were selected applying multistage stratified cluster sampling method. Overweight and obesity were detected using age and sex specific body mass index cut-off points recommended by International Obesity Task Force.

\section{Results}

Among the 1110 children included in the study, the prevalence of overweight was $11.3 \%$ (95\%CI: 9.4-13.2). The prevalence of obesity was $2.2 \%$ (95\% CI: $1.3-3.0)$. The overall prevalence of overweight and obesity were $13.4 \%$ and $13.6 \%$ for female and male respectively. Prevalence of overweight in private schools was higher than in government schools $(\mathrm{p}<0.01)$.

\section{Conclusion}

Prevalence of overweight and obesity in grade five students in schools of Gampaha $\mathrm{MOH}$ area were $11.3 \%$ and $2.2 \%$. Prevalence was higher in private schools.

Key words: children, obesity, overweight, prevalence

\section{Introduction}

Childhood overweight is a serious, large scale health problem worldwide. Prevalence is increasing at an alarming rate both in developed and developing countries. In many developing countries overweight co-exist with under nutrition; leading to double burden ${ }^{(1)}$.SriLanka is in a rapid demographic, epidemiological and nutritional transition. As a consequence, overweight and obesity are becoming an increasingly important public health problem
Childhood overweight and obesity is associated with many adverse effects and health risks including physical and psychosocial problems ${ }^{(2)}$. They are at risk of cardiovascular diseases, diabetic and certain cancers ${ }^{(2)}$.Psychosocial problems are also important even in early schooling years. Social isolation, low self esteem and abnormal behavioural patterns have been commonly reported from European countries ${ }^{(2)}$.Changing physical appearance leads to discrimination and social isolation ${ }^{(3)}$.

\footnotetext{
1. Registrar, Postgraduate Institute of Medicine, University of Colombo.

2. Professor, Department of Public Health, Faculty of Medicine, University of Kelaniya.

Correspondence : upuliaruna@yahoo.com
} 
There are variations in prevalence of overweight in children and adolescents in different parts of the world. A study conducted in Italy for trend analysis of overweight and obesity revealed a rise from $31.7 \%$ to $33 \%$ in nine year old children from 2002 to 2006.For eleven years old children it revealed a decline from $20.7 \%$ to $19.6 \%$ from 2004 to $2006^{(4)}$.Another study in United Status of America showed more than $25 \%$ of children and adolescents are overweight ${ }^{(5)}$.

The prevalence of overweight and obesity in adolescents in Sri Lanka was 6.1\% and the figure for Gampaha district was $8.5 \%$ in $2001{ }^{(6)}$. From another study in an urban area of Sri Lanka, the prevalence of overweight among eight to twelve year old children was detected as between $8 \%$ to $19 \%$ for different age and sex categories ${ }^{(7)}$.Another study revealed that overweight and obesity had been $7.7 \%$ and $2 \%$ respectively in adolescent girls of 13-14 years in municipal council area, Gampaha ${ }^{(8)}$.Although the problem of overweight in adolescents in Sri Lanka is an emerging health problem, the extent of overweight and obesity in grade five students is not known. Therefore the present study was carried out to determine the prevalence of overweight and obesity among grade five students in schools of Gampaha Medical Officer of Health $(\mathrm{MOH})$ area.

\section{Methods}

A school based descriptive cross sectional study was conducted from September to October 2007. The study population consisted of all students, both girls and boys, attending at grade five classes in government, semi government and international schools within the Gampaha $\mathrm{MOH}$ area.

The sample size was calculated using as the prevalence of $14 \%$ and expected error due to sampling as $2.5 \%{ }^{(7)}$. The Calculated sample size was 1110 with the correction of design effect of 1.5. There were 41 government schools, four international schools and one semi government school consisting 3387 students in grade five classes. According to the categorization of schools by the Ministry of Education, there were two of type $1 \mathrm{AB}$ (classes up to grade 13 with $\mathrm{A} / \mathrm{L}$ Science stream), six of type $1 \mathrm{C}$ (classes up to grade 13 with A/L Commerce and Art stream only), 21 of type 2 (classes up to grade 11) and 13 of type 3 (classes up to grade five or eight) in Gampaha MOH area. Multistage stratified cluster sampling method was used to select the sample. Since only one semi-government and four international schools were available, all grade 5 students of these schools were included in to the study. From the government schools one from each category was selected randomly. Therefore altogether nine schools were selected for this study. The informed consent was obtained from their parents before the data collection. All consented students who were present on the day of data collection were included. Date were collected from 783(86.5\%) of 905 government, $227(86 \%)$ of 264 semi-government and 100 (87\%) of 115 international school children for this study.

Record sheets were used as study instruments which consisted of school type, age and sex, date of birth, weight and height of the participants for data collection. Weight and height measurements were taken in a standard way with the student in their school uniform without shoes. Weight was measured in kilograms using one standardized bathroom weighing scale to the closest 500 grams. Height was measured in centimetres using microtoise tape to the nearest $0.1 \mathrm{~cm}$. All measurements were taken by the principle investigator. Overweight and obesity were defined by BMI cut-off points recommended by the International Obesity Task Force (IOTF) with 
age and sex specific cut-off values. ${ }^{9}$ Prevalence of overweight and obesity were calculated with 95\% confidence intervals. Overweight and obesity were also calculated according to the standard developed by the National Centre for Health Statistics (NCHS). Kappa coefficient was respectively calculated for assessing reliability of the overweight and obesity. Ethical clearance was granted by the Ethics Review Committee of the Faculty of Medicine, University of Kelaniya.

\section{Results:}

The study sample included 641 girls and 449 boys. Mean age was 10.1 years (SD 0.4). Mean BMI for girls and boys were almost similar as
$16.0 \mathrm{~kg} / \mathrm{m} 2$ (SD 3.25) and $15.98 \mathrm{~kg} / \mathrm{m} 2$ (SD 3.28). Out of 1110 study sample 126 students were overweight. Therefore the prevalence of overweight was $11.3 \%$ (Table1). Twenty four students were obese. Therefore the prevalence of obesity was $2.2 \%$. The overall prevalence of overweight and obesity was $13.5 \%$. Prevalence of overall overweight and obesity were $13.6 \%$ for boys and $13.4 \%$ for girls (Table 1). Prevalence of overweight in private schools was higher (15.3\%) than in government schools $(12.8 \%)$. The difference was statistically significant $(\mathrm{Z}=4.2$, $\mathrm{p}<0.01)$.Comparing the IOTF and NCHS standards, kappa coefficient for overweight and obesity were 0.97 and 0.61 respectively.

Table 1: Prevalence of overweight and obesity among grade five students in schools of Gampaha MOH area

\begin{tabular}{l|l|l|l}
\hline & Number & $\begin{array}{l}\text { Prevalence } \\
\text { (per 100) }\end{array}$ & $\begin{array}{l}95 \% \text { CI } \\
\text { (per 100) }\end{array}$ \\
\hline Overweight & 126 & 11.3 & $9.4-13.2$ \\
Obesity & 24 & 2.2 & $1.3-3.0$. \\
Overweight and obesity & 150 & 13.5 & $11.5-15.5$ \\
Overweight and obesity for boys & 64 & 13.6 & $10.5-16.7$ \\
Overweight and obesity for girls & 86 & 13.4. & $10.8-16.0$ \\
Overweight and obesity in government schools & 100 & 12.8 & $10.4-15.1$ \\
Overweight and obesity in private schools ${ }^{1}$ & 50 & 15.3 & $11.4-19.2$ \\
\hline
\end{tabular}

${ }^{1}$ statistically significant difference $(\mathrm{Z}=4.2, \mathrm{p}<0.01)$ 
Table 2: Comparison of two standards with regard to overweight and obesity

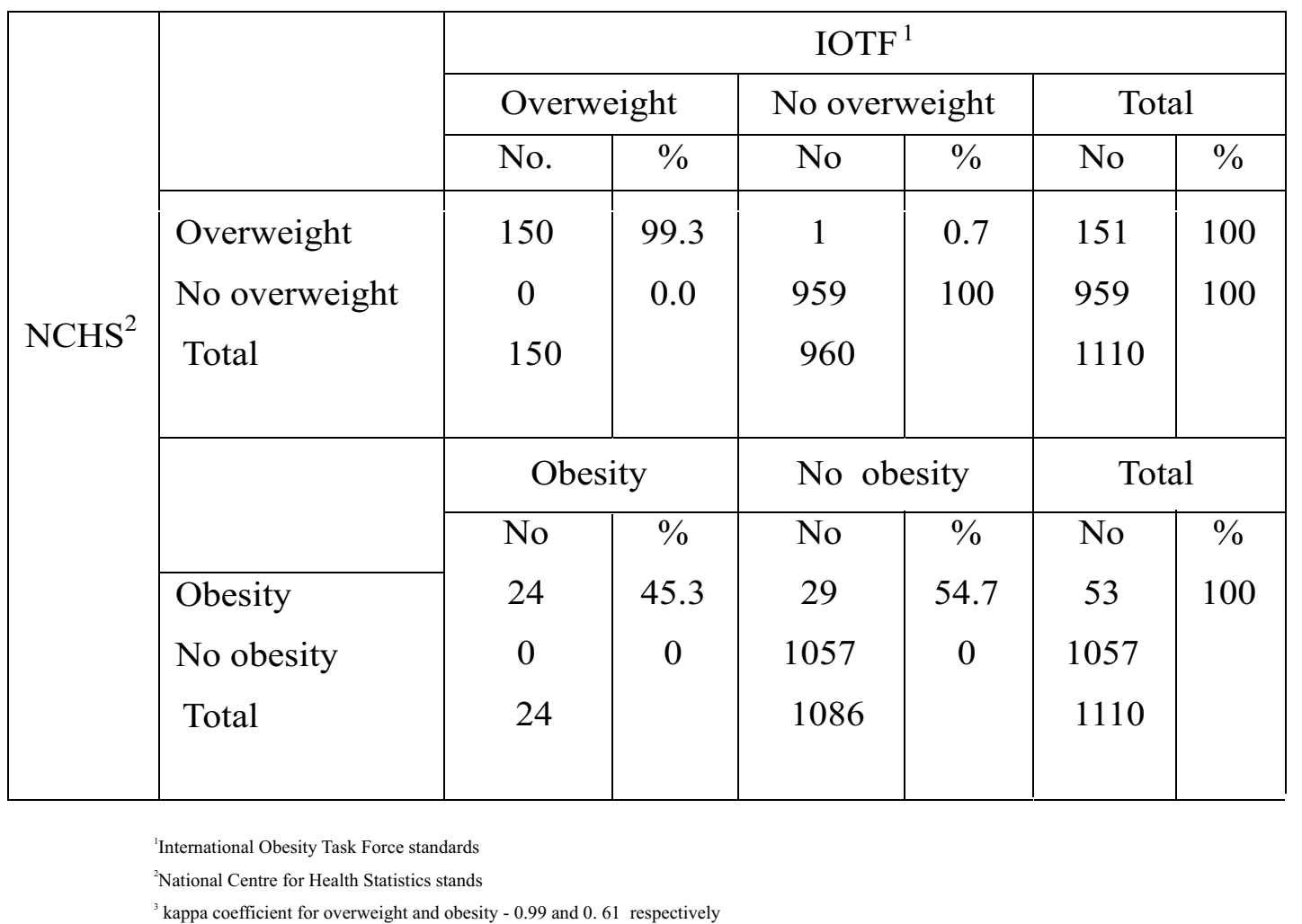

\section{Discussion}

The prevalence of overweight, obesity and overall overweight and obesity of grade five students of schools in Gampaha MOH area were $11.3 \%, 2.2 \%$ and $13.5 \%$ respectively. The overall prevalence is consistent with the results reported by a study conducted in Colombo city area in 2002 which was $14 \%{ }^{(7)}$. As in our study, the previous study also reported that prevalence was higher among private schools compared to government schools ${ }^{(7)}$. By contrast to the previous study we found that there was no statistically significant difference between boys and girls. Jayathissa et al also reported that boys had significantly higher mean BMI than girls in all ages ${ }^{(10)}$.An island wide survey carried out in 2001 revealed the prevalence of overweight and obesity in Gampaha area were $6.5 \%$ and $2.0 \%$. Although the data are not comparable because of the different age range and definition criteria, the results obtained from this study also suggest recent increasing prevalence ${ }^{(6)}$.A study conducted in 2001 among 15 and 16 year old school girls in Colombo Municipal council area showed that the prevalence of overweight was $7.3 \%{ }^{(11)}$. Several studies conducted in European countries had also reported high prevalence of overweight and obesity using the IOTF standard than the current study ${ }^{(12,13,14)}$. The difference may be due to the cultural and social difference in European and Asian regions.

In the current study, the overweight and obesity were defined by BMI cut-off points recommended by the IOTF with age and sex specific cut-off values. The cut-off values are linked to the widely used adult's BMI cut off points of $25 \mathrm{~kg} / \mathrm{m}^{2}$ for overweight and $30 \mathrm{~kg} / \mathrm{m}^{2}$ for obesity. The curve for obesity and overweight are passing through the adult cut off point at age 18 years. These cut-off points are recommended for use in international comparisons of prevalence of 
overweight and obesity ${ }^{(9)}$.Many researchers have used the above cut-off values for assessing overweight and obese ${ }^{(7,8,12,13,14,15)}$. We compared the IOTF and NCHS standards for assessing reliability of defining overweight and obesity. High values of kappa coefficients indicated that reliability was very high between the two standards with regard to overweight.

\section{Conclusions}

The prevalence of overall overweight or obesity was $13.5 \%$ among the children at grade 5 in the schools of Gampaha $\mathrm{MOH}$ area and it was higher among those who attending private schools than public schools.

\section{Acknowledgements}

We acknowledge the financial support provided by the Ministry of health for this study.

\section{References}

1. World Health Organization (2000) Obesity: Preventing and managing the global epidemic: Report of a WHO Consultation on Obesity. Technical Report Series, No.894, WHO, Geneva.

2. The International Life Sciences Institute, Europe Overweight and obesity in Children Task Force. Overweight and obesity in European children and adolescent: causes and consequences prevention and treatment 2000

3. Gortmaker SL, Must A, Perrin JM, Sobol $A M$, Dietz $W H$. Social and Economic Consequences of Overweight in Adolescence and Young Adulthood. The New England Journal of Medicine 1993; 329:1008-1012.

4. Lazzeri G, Rossi S, Pammolli A, Pilato V, Pozzi T, Giacchi MV. Underweight and overweight among children and adolescents in Tuscany (Italy). Prevalence and short-term trends. Journal of Preventive Medicine and Hygiene.2008;49(1):13-21.
5. Troiano RP and Flegal KM. Overweight Children and Adolescents: Description, Epidemiology, and Demographics. Pediatrics 1998; 101(3): 497-504.

6. Piyasena $\mathrm{C}$ and Mahamithawa AMASB. Assessment of anemia status in Sri Lanka, Medical Research Institute of the Department of Health Service, Sri Lanka 2003.

7. Wickramasinghe VP, Lamabadusuriya SP, Atapattu N, Sathyadas G, Kuruparananthan S, Karunarathne P. Dietary and physical activity patterns of school children in an urban area of Sri Lanka. Sri Lanka Journal of Child Health 2005, 34: 44-49.

8. Sudasinghe SPBH. Prevalence and some associated factors of overweight in year eight school girls in girl's only schools in Gampaha municipal council area. Dissertation (Msc.Community Medicine, Postgraduate Institute of Medicine, University of Colombo. 2006).

9. Cole TJ, Bellizzi MC, Flegal KM. Establishing a standard definition for child overweight and obesity worldwide: international survey. British Medical Journal. 2000; 320:1240-1243.

10. Jayathissa R, Mahamithawa S, Ranbanda JM. Nutritional Problems Among Sri Lankan Primary Schoolchildren Aged 5-9 years. Department of Nutrition, Medical Research Institute 2002.

11. Kumarapeli V. A Comparison of the nutritional status and the dietary patterns of adolescent school girls in two defined urban and rural settings, Dissertation (Msc.Community Medicine, Postgraduate Institute of Medicine, University of Colombo; 2001)

12. KaliesH,Lenz, J, Kries R Prevalence of overweight and obesity and trends in body mass index in German pre-school children, 1982-1997. International Journal of Obesity 2002; 26(9):1211-1217. 
13. Toschke, AM, BeyerleinA, Kries R. Children at High Risk for Overweight: A Classification and Regression Trees Analysis Approach. Obesity Research 2000; 13:1270-1274.

14. Canning PM, Courage ML, Frizzell LM Prevalence of overweight and obesity in a provincial population of Canadian preschool children.Canadian Medical Association Journal2004; 171(3): 240242.
15. Veugelers PJ and Fitzgerald AL .Prevalence of and risk factors for childhood overweight and obesity.Canadian Medical Association Journal 2005; 173(6): 607613 